REVES - Revista Relações Sociais, Vol. 05 N. 01 (2022)

https://periodicos.ufv.br/reves

elSSN: 2595-4490

REVES-ReVista Relacōes Sociais (eISSN 2595-4490)

\title{
Interfaces entre Educação Ambiental e extensão universitária
}

Interfaces between Environmental Education and university extension

Cisnara Pires Amaral

ORCID: https://orcid.org/0000-0002-5510-5710 Universidade Regional Integrada do Alto Uruguai e das Missões - URI, Brasil E-mail: cisnara.amaral@urisantiago.br

Amanda Leitão Gindri

ORCID: https://orcid.org/0000-0002-1214-7419

Universidade Regional Integrada do Alto Uruguai e das Missões - URI, Brasil

E-mail: amandagindri@gmail.com

Article Info:

Article history: Received 2021-10-20

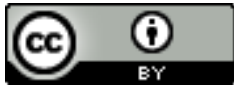

Accepted 2021-11-29

Available online 2021-11-30

doi: 10.18540/revesvl5iss1pp13524-01-09e

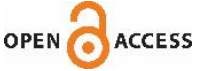

Resumo. Consideramos as várias possibilidades da Educação Ambiental, principalmente nas escolas e universidades, comportando-se como uma possibilidade de desenvolver o protagonismo, a conexão com o conhecimento científico e a capacidade de crítica e autocrítica em relação ao cotidiano. Assim, esse trabalho teve como objetivo pesquisar em uma comunidade escolar, a percepção dos envolvidos em relação ao descarte de medicamentos e sua relação com os desequilíbrios ambientais, proporcionando a autocrítica em relação a mudança de hábitos. A pesquisa conclui a percepção entre desequilíbrios ambientais e meio ambiente, porém, ainda verificamos que continuam realizando descarte inadequado de suas medicações, tanto no lixo como na pia de cozinha, não possuem o hábito de se dirigir a pontos de coleta da cidade e não realizam a relação entre descarte inadequado de medicações e mutações que poderão afetar a água e o solo, interferindo na cadeia alimentar. Sendo assim, a extensão universitária poderá promover a inserção da Educação Ambiental, colaborando para discussões, debates, aprendizado e conhecimento científico, contribuindo para ratificar as diferentes interfaces que esse eixo proporciona, principalmente em relação ao equilíbrio do ecossistema.

Palavras-chave: Desequilíbrios ambientais. Conscientização. Descarte de medicamentos.

Abstract. We consider the various possibilities of Environmental Education, especially in schools and universities, behaving as a possibility to develop a leading role, the connection with scientific knowledge and the capacity for criticism and self-criticism in relation to everyday life. Thus, this work aimed to research in a school community, the 
perception of those involved in relation to the disposal of medications and its relationship with environmental imbalances, providing self-criticism in relation to changing habits. The research concludes the perception between environmental and environmental imbalances, however, we still find that they continue to dispose of their medications inappropriately, both in the garbage and in the kitchen sink, they do not have the habit of going to collection points in the city and do not carry out the relationship between inappropriate disposal of medications and mutations that could affect water and soil, interfering with the food chain. Thus, the university extension will be able to promote the insertion of Environmental Education, contributing to discussions, debates, learning and scientific knowledge, contributing to ratify the different interfaces that this axis provides, especially in relation to the balance of the ecosystem.

Keywords: Environmental imbalances. Awareness. Disposal of medications.

\section{Introdução}

A Educação Ambiental (EA) constitui-se como parâmetro para promover discussões acerca das mazelas ambientais que estamos constantemente expostos, sendo assim a utilização dessa ferramenta dentro do contexto universitário promoverá a cidadania e a percepção de pertencimento e responsabilidade.

Carvalho, Xaxier e Carvalho (2021) relatam que a EA poderá promover mudanças, desde que trabalhada num viés crítico, não sendo delegada somente a área das Ciências da Natureza, sendo assim as pessoas carecem de uma visão global e integrada, que envolve inúmeras inter-relações e requer familiaridade com muitas áreas do conhecimento, como por exemplo a Química, a Biologia, a Geologia, a Oceanografia e a Geopolítica (PINOTTI, 2016).

Nesse contexto de desenvolvimento de cidadania, percepção e criticidade temos um assunto extremamente marcante e pouco explorado nas universidades, 0 descarte incorreto de medicamentos, assunto que necessita ser explorado, pois em qualquer pesquisa rápida ainda será constatado que as pessoas lançam suas medicações em locais inadequados, principalmente o lixo, sendo responsáveis pela contaminação do solo e da água.

Barcelos et al., 2011 relatam fatos preocupantes e pouco discutidos em relação a contaminação ambiental, observando que os medicamentos podem causar dependência física ou psíquica; exemplificando o caso dos antibióticos, antilipêmicos, meios de contraste de raios $x$, anti-inflamatórios, dentre outros fármacos que ocasionam impactos ambientais extremamente relevantes, afetando diversos ecossistemas.

Ainda temos que considerar, a cultura brasileira de automedicação e a fácil aquisição desses produtos acabaram por gerar nas residências brasileiras um acúmulo de medicamentos. As "farmacinhas caseiras", como são conhecidas, geralmente contêm algumas fórmulas reservadas às emergências (antigripal, analgésicos, antitérmicos). É muito comum conter sobras de medicamentos controlados (antibióticos, entre outros) que provavelmente não mais serão utilizados, mas que ficam guardados até a expiração da sua data de validade (BUENO; WEBER; OLIVEIRA, 2009).

Essa cultura da automedicação está relacionada as diversas propagandas que estimulam os consumidores a adquirir produtos, que muitas vezes ficam guardados 
na prateleira e não são utilizados. Mendes et al., 2010 relatam que são vários os fatores que resultam na geração de resíduos de medicamentos, entre eles se destacam as propagandas na mídia, que estimulam o consumidor a adquirir medicamentos sem necessidade, caixas de medicamentos contendo mais do que o médico irá prescrever, autoconsumo, e a alteração de um medicamento por outro durante o tratamento de alguma doença.

Serão necessárias intervenções para que a comunidade perceba essa situação agravante e desenvolva a cidadania em relação a tema tão controverso. Souza e Falqueto (2015) relatam que existe a necessidade de informar aos consumidores os riscos ao meio ambiente e a saúde da população do descarte inadequado dos medicamentos domiciliares, e a partir daí, desenvolver mecanismos eficientes para a coleta e destinação segura dos mesmos.

Essa é uma das tentativas de sustentabilidade, pois entendemos que o descarte incorreto de medicamentos acaba desencadeando sérios problemas tanto ao meio ambiente quanto à saúde humana, devido aos resíduos dos medicamentos, que apresentam substâncias químicas na sua composição, de acordo com o potencial inflamável, reativo, corrosivo e radiativo (PFLUGSEDER, 2015).

Carvalho, Xavier e Carvalho (2021) afirmam que a EA promoverá o entendimento das questões ambientais desde que haja intencionalidade em suas práticas que conduzirá ao enfrentamento da problemática ambiental.

Importante lembrar que os fármacos não são removidos pelos tratamentos de água convencionais, já que suas propriedades químicas são persistentes, têm alto potencial para bioacumulação e baixa biodegradabilidade. Por isso, não há método sanitário que os retire completamente da água, mesmo em uma rede de tratamento de esgoto (CRESTANA; SILVA, 2011).

Outro aspecto a ser abordado é que, na maioria das cidades brasileiras, o lixo ainda é despejado em lixões, possibilitando que principalmente os catadores consumam inapropriadamente os medicamentos ou os descartem diretamente no solo, para o reaproveitamento das embalagens. O consumo indevido de medicamentos, principalmente os de data de validade expirada, pode levar ao surgimento de reações adversas graves, intoxicações, entre outros problemas, comprometendo decisivamente a saúde e a qualidade de vida dos usuários (ANVISA, 2011).

Pinto et al., (2014) observam que o avanço da ciência na área da saúde proporcionou um aumento na fabricação de medicamentos, que na maioria das vezes, depois de vencidos, são descartados de maneira inadequada, geralmente no lixo comum e ainda afirmam que a questão que era apenas ambiental permeia pelos aspectos econômico e social em igualdade de importância. Por último, ressaltam que para alcançar a sustentabilidade ambiental é necessário investir em campanhas de esclarecimento, que podem ter no final um alto resultado.

Torna-se imprescindível, trabalhos de extensão acadêmica para discussão, análise, informação e aprendizado, utilizando a Educação Ambiental como ferramenta para estimular a mudança de hábitos e atitudes, principalmente, em relação ao descarte incorreto de medicações.

\section{Metodologia}

O trabalho de extensão, está relacionada ao Projeto Integrador do Curso de Farmácia da Universidade Regional Integrada do Alto Uruguai e das Missões, URICâmpus Santiago/RS, foi realizado na disciplina de Genética Básica e Molecular pelos 
acadêmicos do IV semestre do Curso de Farmácia, estabelecendo a conexão entre os temas: Mutações, Descarte Incorreto de Medicações e Educação Ambiental.

O objetivo do tema foi de realizar a relação do descarte incorreto de medicamentos, identificando o local de descarte, o deslocamento até os pontos de coleta e se as pessoas tinham noções sobre a influência do descarte incorreto com a mudança no material genético e consequente desequilíbrio ambiental.

O cenário da pesquisa foi uma escola pública localizada em um bairro central do município de Santiago/RS. Para tal, realizou o zoneamento das quadras que envolviam a escola, totalizando 100 residências. A pesquisa ocorreu durante um mês, nos sábados, pela manhã e tarde.

Os acadêmicos visitavam as residências, expondo o objetivo do trabalho, propondo aos moradores que respondessem um questionário semiestruturado. Após as visitas, ocorria o convite para as palestras relacionadas aos assuntos, que ocorreram na escola, durante as manhãs e noites, como forma de apresentar a pesquisa e munir a comunidade de informações, proporcionando Educação Ambiental em relação a um tema pouco abordado.

As palestras contaram com 168 discentes matriculados no ensino médio e ensino fundamental (anos finais) durante uma manhã do mês junho e 180 indivíduos no turno da noite, alunos de ensino médio, Educação de Jovens e Adultos (EJA), pais e familiares moradores dos arredores da escola.

Após a pesquisa ocorreu a tabulação e análise de dados.

\section{Resultados e discussão}

Seguem resultados dos questionários aplicados em 100 residências da comunidade escolar Cristóvão Pereira, localizada na cidade de Santiago/RS, na zona central.

A figura 1 relaciona o descarte das medicações na comunidade pesquisada.

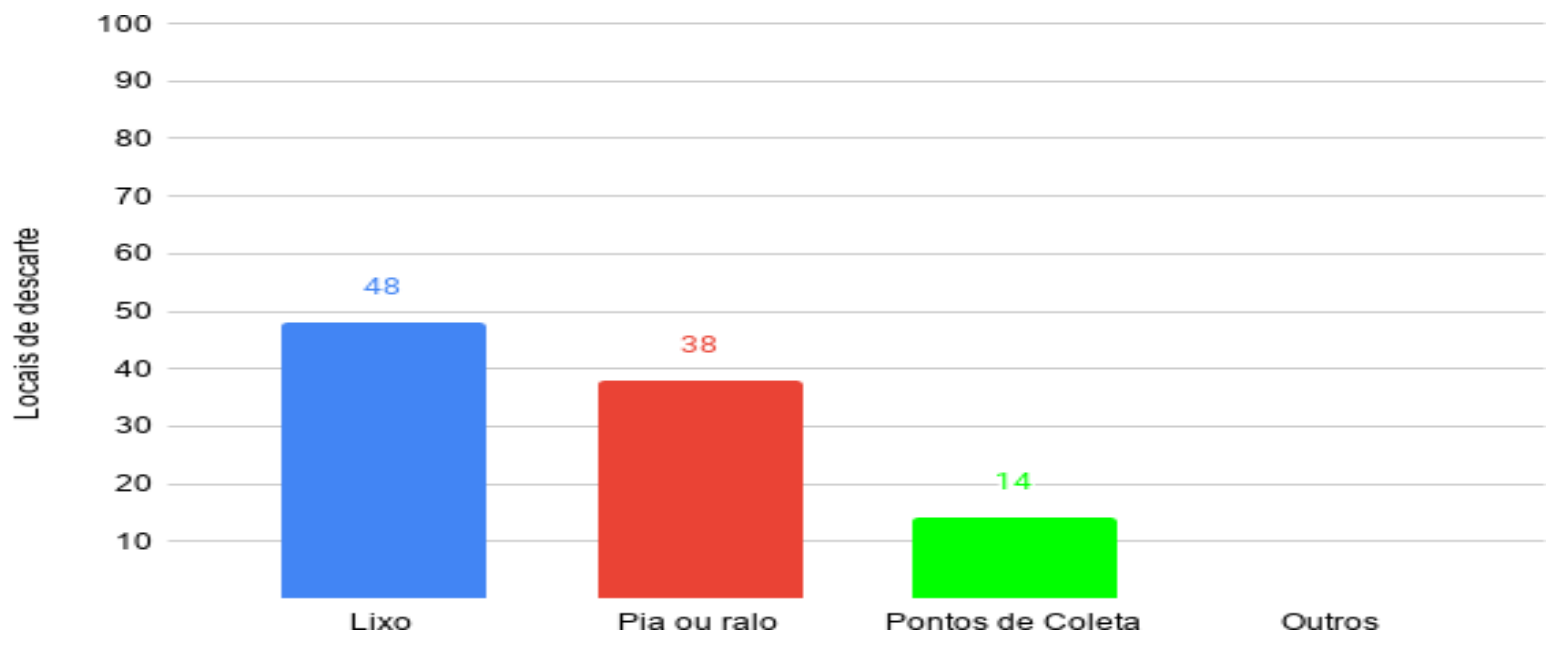

Figura 1 - Descarte de Medicações. (Fonte: Elaborado pelas autoras). 
Em relação ao resultado observa-se que dos 100 entrevistados $48 \%$ das pessoas jogam suas medicações vencidas no lixo, 38\% utilizam a pia ou ralo de cozinha e $14 \%$ armazenam em pontos de coleta. Isso nos deixou extremamente preocupados, pois nenhum dos entrevistados mantém o hábito de se deslocar até os pontos de coleta, localizados em duas farmácias, no mesmo bairro onde está inserida a escola. Este fato nos remeteu a questionar se as pessoas entendem o problema que poderão causar ao meio ambiente. A partir deste dado, produzimos um programa realizado em parceria com a rádio da Universidade para discutir os resultados e alertar a população sobre os danos e consequências dessa atitude, que poderá impactar a saúde da população.

Ressalta-se que na natureza ocorrem ciclos e que os compostos presentes nessas corpo dos indivíduos podendo causar vários males. Um estudo realizado por Zuccato et al. (2006), revelou a presença de resíduos de fármacos em corpos hídricos e sua contaminação resulta da excreção de metabólitos, tanto por seres humanos quanto por animais e do descarte indevido desses compostos diretamente na rede de esgoto.

Outro fato importante discutido por Rodrigues (2009) está relacionado aos medicamentos que são expostos a céu aberto, fazendo parte do lixo, disseminando doenças, por meio de vetores que se multiplicam nesses locais ou que fazem desses resíduos fonte de alimentação. cidade.

A figura 2 discute o deslocamento até os pontos de coleta distribuídos na

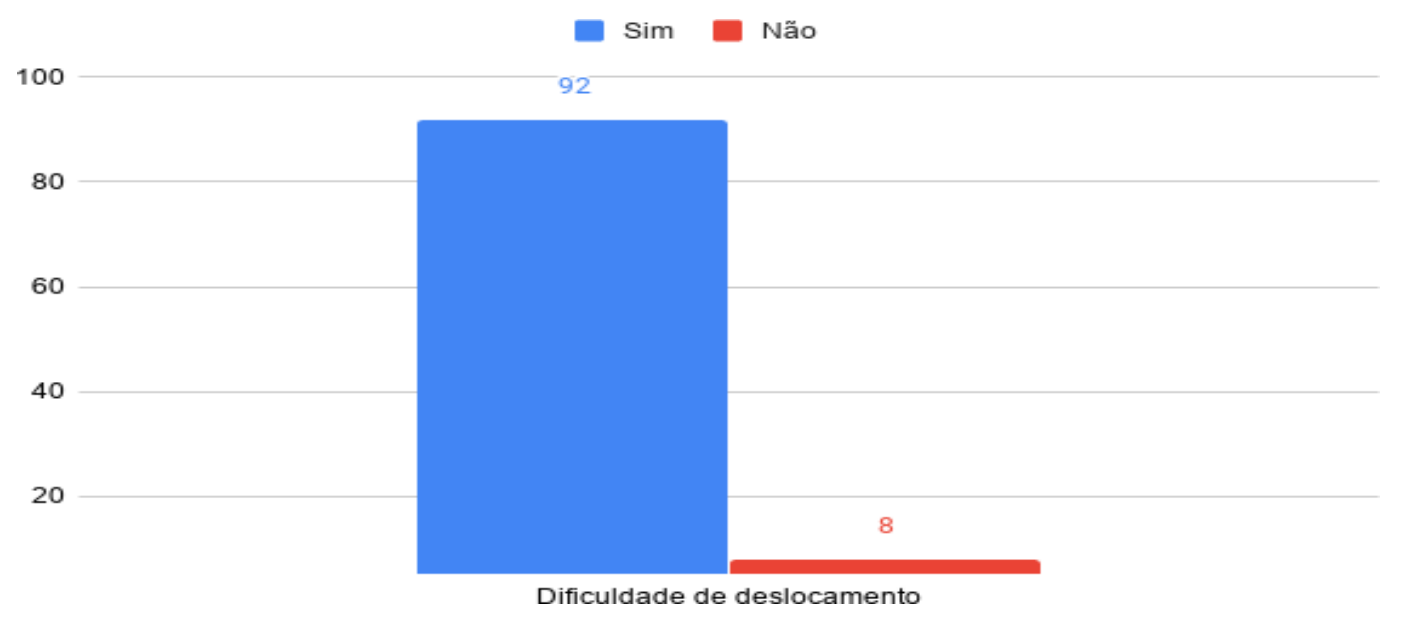

Figura 2 - Pontos de Coleta. (Fonte: Elaborado pelas autoras).

Nota-se que $92 \%$ dos entrevistados acreditam que a dificuldade está em se deslocar até os pontos de coleta. Quando interrogados sobre os motivos, acabaram marcando: esquecimento, desleixo, falta de informações sobre o que as medicações poderiam ocasionar no meio ambiente, falta de informações sobre as localizações dos pontos de coleta. Acredita-se que os pontos de coleta deveriam ser ampliados, inclusive serem encontrados até mesmo nas escolas, que a Secretaria do Meio Ambiente e da Saúde poderiam promover campanhas de conscientização, coleta porta a porta. Estas poderiam ser algumas formas de evitar um impacto ao meio ambiente, auxiliando na promoção da saúde.

Pinto et al (2014) relatam que existe a necessidade imediata, por parte do poder público, de se veicular campanhas de esclarecimento, utilizando os principais meios de comunicação como a rádio, a internet e a TV, principalmente no horário nobre, a fim de maximizar o alcance do descarte correto de medicamentos. 
A pergunta 3 relaciona a compreensão da comunidade em relação ao descarte de medicações, as mutações e os desequilíbrios que ocorrem no meio.

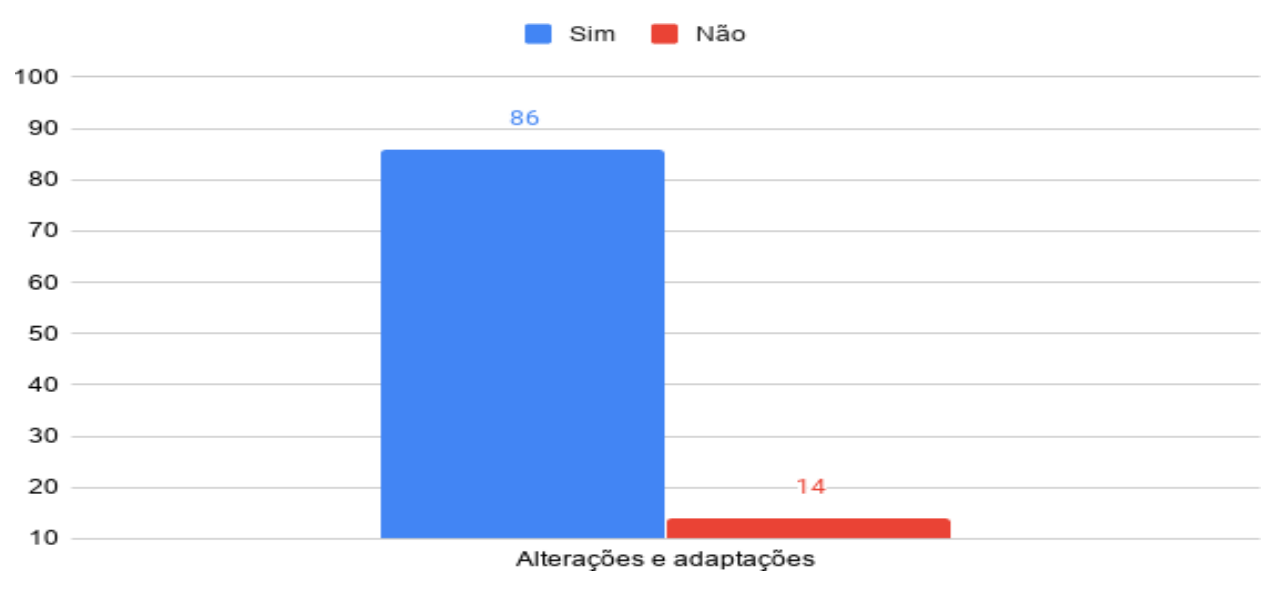

Figura 3 - Relação do descarte inadequado e suas consequências. (Fonte: Elaborado pelas autoras).

Percebe-se que $86 \%$ dos entrevistados têm consciência sobre as consequências que poderão acarretar no meio. O que podemos elencar sobre isso? Têm consciência? Mas a preguiça, o desleixo, a incompreensão, em relação ao tema falam mais alto? É difícil entender a espécie humana, queixosa quando ocorrem desastres ambientais, porém difíceis de perceber-se parte do meio, difíceis em realizar atitudes adequadas que colaborem para o equilíbrio do ecossistema.

Sabemos que essa espécie é imediatista, que o capitalismo é elo base dessa sociedade, capaz de impactar o meio às custas do capital, por isso acreditamos que é fundamental a atuação docente. Essa atuação poderá proporcionar momentos de reflexão e criticidade.

Nunca é demais destacar que o aluno constrói seu próprio conhecimento, jamais o recebe pronto, salvo em ações mecânicas onde esses conhecimentos jamais ajudarão construir outros, seu professor na verdade o ajuda nessa tarefa de construção, intermedia a relação entre o aluno e o saber, mas é uma ajuda essencial, imprescindível, pois é graças a ela, que o aluno, partindo de suas potencialidades, pode progredir na direção das finalidades educativas (ANTUNES, 2015).

Desse modo, o intuito do trabalho traz à tona discussões, tanto no meio acadêmico, quanto na comunidade escolar. A pesquisa, a troca de informações e os questionamentos ocorridos poderão servir para que os assuntos relacionados ao meio ambiente e suas várias interfaces, não passem despercebidos, nem sejam esgotados em um único trabalho.

Também devemos considerar as questões referente ao tema "mutações", palavra que raramente fazia parte do vocabulário da maioria das pessoas, porém já fazem alguns anos que passou a ser muito veiculada na mídia, principalmente em relação às epidemias de Dengue Zika vírus, Febre Amarela e Chikungunya, pelas diferentes formas de adaptações, tanto do mosquito, quanto do vírus. Obviamente, temos que considerar que as pessoas podem conhecer o tema, porém não associam o desastre ambiental com as mudanças no DNA. 
A pergunta 4 está relacionada ao conhecimento sobre o termo "mutação".

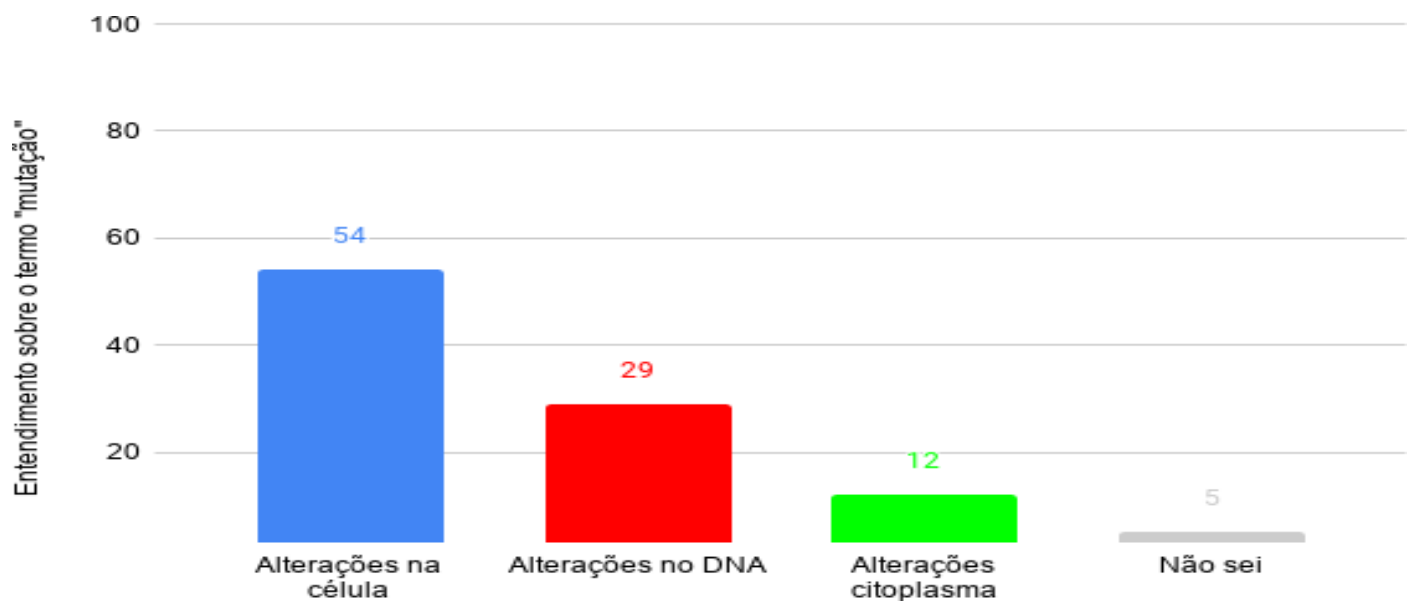

Figura 4 - Compreensão em relação ao termo "mutação". (Fonte: Elaborado pelas autoras).

Além do tema ser estudado no decorrer do Ensino Médio, estar recorrente nas mídias relacionado a muitas patogenias, observamos que as pessoas tem noção que "mutação" é um termo que faz referência a alguma alteração do organismo, porém ainda traz um certo grau de dificuldade, principalmente em relação às definições exatas, fato observado nas diferentes escolhas dos entrevistados. Destarte, necessitamos de divulgação, munindo as comunidades com informações sobre as diferentes formas de alterações que poderá sofrer o material genético em contato com agentes teratogênicos, pois é necessário que as comunidades tenham consciência que o material genético dos organismos poderá sofrer modificações e alterar as cadeias alimentares, ocasionando desequilíbrios que podem ser teciduais, hormonais ou celulares.

Amabis e Martho (2018) consideram que as mutações são a fonte primária da variabilidade gênica. Originam-se de alterações, que ocorrem ao acaso, na sequência de bases nitrogenadas de determinado gene durante a duplicação da molécula de DNA. Essa alteração pode ser causada pela perda, adição ou substituição de nucleotídeos, o que pode originar um gene capaz de codificar outra proteína.

Salientamos a importância dessas conexões, para que os jovens consigam compreender as relações que se estabelecem na natureza. Faro (2017) observa que no atual momento de constantes perturbações naturais que a humanidade atravessa, não há outra atitude a tomar senão trabalharmos por uma sociedade informada, sustentável e consciente de seu pertencimento à escola da vida, de sua relação com o meio ambiente. 


\section{Considerações Finais}

Conclui-se que as atividades de extensão universitárias atreladas a EA, proporcionam debates, criticidade, instigam conhecimento científico e compreensão sobre as mazelas que a comunidade vivencia. Oportuniza a reflexão, principalmente em relação a temas ambientais, pouco discutidos, como é o caso do descarte de medicamentos.

Verificou-se que a maioria da comunidade tem noção sobre os desequilíbrios ocasionados no meio ambiente; porém, não possuem conhecimentos científicos adequados acerca da atuação dessas medicações em solo ou água, não possuem hábitos de se deslocar até os pontos de coleta para realizar o descarte adequado. Em suma, existe a conscientização, porém a tomada de decisões em relação a mudança de hábitos e atitudes ainda precisa ser discutida, pois ainda encontramos uma quantidade considerável de pessoas que jogam suas medicações no lixo ou pia de cozinha, esse fato demonstra que os metabólitos secundários certamente afetarão o ecossistema, pois estarão em contato com a água e o solo.

Compreendemos a importância dessas atividades para proporcionar o protagonismo tanto do acadêmico, quanto do público entrevistado, pois acreditamos que ao discutir as questões ambientais podemos desenvolver as ideias de responsabilidade, pertencimento e senso crítico.

\section{Agradecimentos}

À Comunidade Escolar do Colégio Estadual Cristóvão Pereira/RS.

\section{Referências}

AMABIS, José M.; MARTHO, Gilberto R. Fundamentos da Biologia Moderna. 1 ed. São Paulo: Moderna, 2018.

ANTUNES, Celso. Vygotski, quem diria?! Em minha sala de aula. 10 ed. Petrópolis, RJ: Vozes, 2015.

BARCELOS, Mônica N. et al. Aplicação do método Failure Mode and Effect Analysis (FMEA) na identificação de impactos ambientais causados pelo descarte doméstico de medicamentos. Engenharia Ambiental. v.8, n.4, p. 62-68, 2011.

BRASIL. Agência Nacional de Vigilância Sanitária (ANVISA). Descarte de medicamentos: responsabilidade compartilhada. Brasília: Anvisa, 2011. Disponível em: http://www.anvisa.gov.br, acesso em fev 2018.

BUENO, Cristiane S.; WEBER, Débora; OLIVEIRA, Karla R. Farmácia Caseira e Descarte de Medicamentos no Bairro Luiz Fogliatto do Município de ljuí - RS. Revista de Ciências Farmacêuticas Básica e Aplicada, v. 30, n. 2, p. 75-82, 2009.

CARVALHO, Arnaldo H.O.; XAVIER, Gabriela P.; CARVALHO, Vânia A.O. A Educação Ambiental na perspectiva dos estudantes do curso de pós graduação do IFES, campus Ibatiba. RevBea, v.16, n.5, p.156-174, 2021.

CRESTANA, Giuliana B.; SILVA, Jorge H. Fármacos residuais: panorama de um cenário negligenciado. Revista Internacional de Direito e Cidadania, n. 9, p. 55-65, 2011.

FARO, Isaías. Educação para o Meio Ambiente. Campinas, SP: Pontes Editores, 2017.

MENDES, Zilda et al. Desperdício de medicamentos no ambulatório em Portugal. Rev Port Clin Geral. v. 26, p. 12-20, 2010. 
PINTO, Glaucia M. F. et al. Estudo do descarte residencial de medicamentos vencidos na região de Paulínia (SP), Brasil. Revista Engenharia Sanitária e Ambiental, v.19, n.3, p. 219-224, 2014.

PINOTTI, Rafael. Educação Ambiental para o século XXI: no Brasil e no mundo. 2 ed. São Paulo: Blucher, 2016.

PFLUGSEDER, Carla A. Avaliação da logística reversa de medicamentos no município de Lajeado/RS. 2015. 95 f. Trabalho de Conclusão de Curso, Univates, Lajeado, RS, 2015.

RODRIGUES, Carla R. B. Aspectos legais e ambientais do descarte de resíduos de medicamentos. 2009. 110 f. Dissertação (Mestrado em Engenharia de Produção). Universidade Tecnológica Federal do Paraná, Ponta Grossa, 2009.

SOUZA, Carla P. F. A.; FALQUETO, Elda. Descarte de medicamentos no meio ambiente no Brasil. Rev. Bras. Farm. n.96, v.2, p.1142-1158, 2015.

ZUCCATO, Ettore et al. Pharmaceuticals in the environment in Italy: causes, occurrence, effects and control. Envir. Sci. Pollut. Res. Int.v.13, n.1, p. 15-21, 2006. 